\title{
NOX4: a potential therapeutic target for pancreatic cancer and its mechanism
}

\author{
Yawei $\mathrm{Bi}^{1 \dagger}$, Xiao Lei ${ }^{2+}$, Ningli Chai ${ }^{1 *}$ and Enqiang Linghu ${ }^{1 *}$
}

\begin{abstract}
Nicotinamide adenine dinucleotide phosphate (NADPH) oxidase 4 (NOX4) is one of the seven isoforms of NOX family, which is upregulated in pancreatic cancer cell, mouse model of pancreatic cancer and human pancreatic cancer tissue. NOX4 is a constitutively active enzyme that primarily produces hydrogen peroxide, which exhibits completely different properties from other subtypes of NOX family. More importantly, recent studies illuminate that NOX4 promotes pancreatic cancer occurrence and development in different ways. This review summarizes the potential roles and its mechanism of NOX4 in pancreatic cancer and explores NOX4 as the potential therapeutic target in pancreatic cancer.
\end{abstract}

Keywords: NADPH Oxidase 4, Pancreatic cancer, Reactive oxygen species

\section{Introduction}

Pancreatic cancer (PC) is a highly malignant digestive system tumor with a poor prognosis. Despite advances in medicine has improved the survival rate of many types of aggressive cancer, $\mathrm{PC}$ remains one of the deadliest malignancies with an incidence/mortality ratio of as high as $94 \%$ and a 5 -year survival rate of about $9 \%$ [1]. It is predicted that PC will rise to the second-leading cause of cancer-related deaths in the U.S. in 2030 [2]. Therefore, it is urgent for us to explore the pathogenesis of $\mathrm{PC}$ and search its potential therapeutic targets. PC has a complex landscape of genetic alterations with prevalent chromothripsis and mutations in KRAS, TP53, SMAD4, and CDKN2A [3-5]. However, heterogeneous and complex compositions of genetic alterations may, in concert, drive common phenotypes that expose specific vulnerabilities. One such phenotype that has emerged as a potential vulnerability in cancer is aberrant redox homeostasis [6].

Reactive oxygen species (ROS) exerts oxidative stress in the cells which deregulate the redox homeostasis

\footnotetext{
*Correspondence: csxlily@163.com; linghueq301@163.com

${ }^{\dagger}$ Yawei Bi and Xiao Lei contributed equally to this work

1 Department of Gastroenterology and Hepatology, The First Medical Center of PLA General Hospital, Beijing 100853, China

Full list of author information is available at the end of the article
}

and promote tumor formation by initiating an aberrant induction of signaling networks that cause tumorigenesis [7]. ROS is a by-product of cell metabolism, including superoxide anions, hydroxyl radicals and hydrogen peroxide. Nicotinamide Adenine Dinucleotide Phosphate (NADPH) oxidases are a major intracellular source of ROS, and evidence suggests that ROS production by NADPH species can strongly influence both tumor growth and survival $[8,9]$. Over the decades, six human homologs of the catalytic subunits of the phagocyte NOX were found: NOX1, NOX3, NOX4, NOX5, DUOX1 and DUOX2.Together with the NOX2/gp91phox component present in the phagocyte NADPH oxidase assembly itself, the homologs are now referred to as the NOX family of NADPH oxidases. The isoforms of NOX are distributed in different tissues, cells and subcellular structures, produce corresponding products, and perform specific functions under physiological and pathological conditions [10].

NOX4 is identified as a nonphagocytic novel NOX in kidney in 2001. Then researchers found that NOX4 is expressed in not only kidney tissues, but also lung, ovarian, pancreas and other organs [11-13]. Unlike other isoforms, NOX4 is a constitutively active enzyme. It produces $\mathrm{H}_{2} \mathrm{O}_{2}$ as the sole or vast majority of detectable ROS product even in vitro in the absence of superoxide

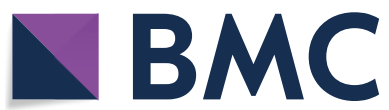

(c) The Author(s) 2021. Open Access This article is licensed under a Creative Commons Attribution 4.0 International License, which permits use, sharing, adaptation, distribution and reproduction in any medium or format, as long as you give appropriate credit to the original author(s) and the source, provide a link to the Creative Commons licence, and indicate if changes were made. The images or other third party material in this article are included in the article's Creative Commons licence, unless indicated otherwise in a credit line to the material. If material is not included in the article's Creative Commons licence and your intended use is not permitted by statutory regulation or exceeds the permitted use, you will need to obtain permission directly from the copyright holder. To view a copy of this licence, visit http://creativecommons.org/licenses/by/4.0/. The Creative Commons Public Domain Dedication waiver (http://creativeco mmons.org/publicdomain/zero/1.0/) applies to the data made available in this article, unless otherwise stated in a credit line to the data. 
dismutase [14]. Compared with other members of the NOX family, NOX4 widely expressed in many different tissues and has a wider range of biological functions. As the main endogenous ROS source, NOX4 is involved in regulating multiple functions of cells including cell proliferation, migration and death [15]. NOX4 generates lower level of ROS which serve as second messengers to induce a panel of intracellular signaling pathways such as HIF2- $\alpha$, p38 MAPK, TGF- $\beta 1 /$ Smad2/3, Akt, Caspase3 to regulate functions of cells [15]. However, when some stimulation signals are received, NOX4 could generate high level of ROS and cause the activation of multiple downstream signal pathways which may promote disease development. Preliminary immune-histological and gene expression surveys of human primary tumor samples have revealed elevated NOX4 protein or transcript levels relative to adjacent normal healthy tissues in several tumor types $[11,16,17]$. The data from gene and protein profiling, cell lines, mouse model and human PC tissues suggest that NOX4 expression is significantly increased in PC which reminds us that NOX4 may play a vital role in the development of PC $[18,19]$. Previous studies have shown that NOX4 participates in PC progression via different ways [20-22]. However, the specific mechanism of NOX4 in the occurrence and development of $\mathrm{PC}$ remains unclear. In this review, we summarize the currently available evidence regarding the role and the mechanism of NOX4 in PC and its possibility as a potential target for the treatment of $\mathrm{PC}$.

\section{NOX4 is involved in the pancreatic tumorigenesis}

The human NOX4 gene comprises 18 exons and is located on chromosome 11q14.2-q21 [23]. NOX4 is quite different from other NOX isoforms as it primarily produces $\mathrm{H}_{2} \mathrm{O}_{2}$ due to a unique third extracytosolic loop (E-loop) [14]. Of the multiple types of ROS, $\mathrm{H}_{2} \mathrm{O}_{2}$ is an adept signaling molecule. $\mathrm{H}_{2} \mathrm{O}_{2}$ is a relatively stable oxidant that is able to cross membranes and react with protein thiol moieties to produce post-translational modifications, altering protein function [[12]. Recent studies showed NOX4 was closely associated with the occurrence and development of different cancers [24-26]. Moreover, NOX4 was upregulated in PC $[18,21]$. Therefore, we consider that NOX4 plays a vital role in PC progression. The potential mechanisms of NOX4 in PC are as follows.

\section{NOX4 regulates $\mathrm{PC}$ cells from death}

One reason why $\mathrm{PC}$ is so aggressive and unresponsive to treatments is its resistance to apoptosis. Previous research showed that the antiapoptotic effects of growth factors in PC cells are mediated via ROS produced by NOX4 [27]. Moreover, Mochizuki pointed out that ROS generated by NOX4 transmit cell survival signals through the AKT-ASK1 pathway and Jong showed that NOX4 generated ROS promote PC cell survival via inhibiting JAK2 dephosphorylation by tyrosine phosphatasesin [28, 29].

Cell senescence is the process by which cells stop dividing and lose their ability to proliferate. Therefore, cellular senescence plays a crucial role in suppressing cancer [30]. ROS have been proposed to be signaling molecules that mediate proliferative cues. However, ROS may also cause DNA damage and proliferative arrest. How these apparently opposite roles could be reconciled, especially in the context of oncogene-induced cellular senescence, which is associated both with aberrant mitogenic signaling and DNA damage response (DDR)-mediated arrest, is unclear. Ogrunc et al. showed that NOX4 promotes transformation of oncogene-expressing PC cells by generating mitogenic ROS, and transformed cell cause inactive DDR and oncogene-induced cellular senescence bypass [19]. Therefore, NOX4-dependent ROS are indeed mitogenic signaling molecules that fuel oncogene-driven aberrant cell proliferation in PC.

\section{NOX4 promotes fibrosis in PC}

In the occurrence and progression of $\mathrm{PC}$, the most significant feature is the formation of pancreatic fibrosis. In this process, pancreatic fibrosis creates a microenvironment of hypo perfusion, hypoxia, and immune shielding in pancreatic tissue, which brings treatment more difficult [31]. NOX4 has been proven to play an important role in the fibrosis process of different organs. Zhao et al. found upregulation of NOX4 in the myocardium causes cardiac remodeling through activating Akt-mTOR and NF- $\mathrm{KB}$ signaling pathways [32]. In fibrotic lung disease, NOX4 expression is increased and plays a deleterious role by reducing fibroblast apoptosis, leading to fibroblast accumulation and fibrosis progression [33]. In kidney, alcohol promotes renal fibrosis by activating NOX4mediated DNA methylation of Smad7 [34].

The key to pancreatic fibrosis is the activation of pancreatic stellate cells (PSCs). Although previous studies found that NOX enzymes play a crucial role in the activation of PSCs and extracellular matrix (ECM) formation [35-37], the specific role of NOX4 in the process of pancreatic fibrosis has not been extensively studied. While it is worth noting that the process of pancreatic fibrosis is similar to liver fibrosis. Like pancreatic fibrosis, the key of hepatic fibrosis is closely related to the activation of hepatic stellate cells (HSCs). Normally, PSCs or HSCs are quiescent and regulate ECM production. However, PSCs and HSCs are activated by many stimulating factors during tumorigenesis $[38,39]$. Then, active PSCs or HSCs can create a suitable microenvironment and facilitate 
cancer progression by altering four processes in hepatic cancer or PC models: excessive fibrosis, promoting tumor metastasis, inducting resistance of chemotherapy and radiotherapy and immune modulation [40, 41].

Plenty of researches already proved that NOX4/ROS signaling pathway promotes the proliferation and activation of HSCs [42-46]. Moreover, experiments using siRNA against NOX4 attenuated HSCs activation, and more importantly, knocking down NOX4 in activated myofibroblasts could reverse the fibrotic phenotypes [47, 48]. In summary, NOX4 is involved in fibrosis of different organs, especially in liver. And considering the similarity between the process of pancreatic fibrosis and liver fibrosis, we believe that NOX4 also plays a key role in pancreatic fibrosis. However, the role of NOX4 in pancreatic fibrosis deserves further study.

\section{NOX4 contributes to EMT in PC}

The epithelial-mesenchymal transition (EMT) process is a major contributor to the development of resistance in multiple cancer types including PC [49]. Classical EMT involves a phenotypic change in cells, in which cells loss their epithelial phenotype, such as tight cell-to-cell adhesion and apical-basal polarity, and acquire a highly invasive, mesenchymal phenotype [50]. Accumulating evidence suggest that EMT plays an important role in the pathogenesis, invasion, metastasis, and drug resistance in PC [51-53]. Notably, many key EMT regulators were recently found to be redox-sensitive, enabling the elucidation of the molecular basis of EMT from a redox perspective. ROS, an important cellular secondary messenger containing free radical species, can alter the biological functions of redox-sensitive proteins involved in ECM remodeling and cell mobility, thereby regulating EMT $[54,55]$. One of the primary sources of ROS production is via NOX enzymes and previous studies proved NOX4 is involved in the EMT process in different organs such as lung, kidney, liver, cervix and breast [24, 56-59].

The role of NOX4 in the EMT process of PC has also been studied. Ma et al. showed that NOX4 mRNA correlation with EMT gene expression such as collagen (COL1A2, COL3A1, COL5A2), metalloproteases (MMP2, MMP9) and fibronectin (FN1) [21]. Risako et al. treated the PC cells with the NOX4 inhibitor diphenylene iodonium and NOX4 siRNAs, the results showed downregulation of NOX4 blocked TGF- $\beta$-induced EMT phenotype including morphological changes, augmented migration, and altered expression of E-cadherin and Snail in PC cells, which showed that NOX4 transmit TGF$\beta$-triggered EMT signals in PC [11]. David et al. suggest that TGF- $\beta 1$-induced EMT in PC cells is mediated through RAC1/NOX4/ROS/p38 MAPK cascade [60]. Recent research showed that NOX4 caused inactivation of lysine demethylase $5 \mathrm{~A}$, increased the methylation modification of histone $\mathrm{H} 3$ and regulated the transcription of EMT associated gene SNAIL1. And NOX4 deficiency repressed hypoxia-induced EMT in PC cells [61]. To sum up, NOX4 and NOX4-mediated ROS generation play vital roles in regulating EMT process in PC.

\section{NOX4 plays a vital role in metabolic regulation}

Metabolism reprogramming is the hallmark of tumor cells, and it has a causal relationship with the occurrence and development of tumors. Regulated metabolic changes in tumor cells include aerobic glycolysis (the Warburg effect), increased glucose uptake, abnormally active glutamine metabolism, and the use of non-primary energy-supply substances for energy supply [62]. These metabolic changes satisfy the rapid growth of tumor cells. The strong energy and material requirements during proliferation help cells adapt to the hypoxic tumor microenvironment, and then provide energy and material support for tumor proliferation, invasion, migration and other biological activities [63].

NOX4 has been reported as a glycolytic regulator in different tissues. Tang et al. used papillomatosis thyroid cancer cells to study the cell growth by knocking down the expression of NOX4 and knocking out its functional partner p22phox/CYBA, the results suggested that NOX4 participated in regulating glycolysis through mROS-HIF1 $\alpha$ pathway, thereby mediating proliferation in thyroid carcinomas [26]. In terms of human neuroblastoma cells, it is showed that knockdown of NOX4 expression by siRNA inhibited glycolysis induced by hypoxia through decreasing the expression of glycolysis-related proteins (HIF-1 $\alpha$, LDHA, and PDK1), decreasing glucose uptake, lactate production, and ROS production, while increasing mitochondria membrane potential [64]. Zeng et al. revealed NOX4 promotes glycolysis, contributing to non-small cell lung cancer growth, and supports glutaminolysis for oxidative resistance [65]. David et al. proved that disturbed flow could increases NOX4 and ROS to stabilize endothelial HIF- $1 \alpha$ which stimulates glycolysis in endothelial cells and then results in vascular inflammation and ultimately atherosclerosis [66]. In respect to the metabolic change in $\mathrm{PC}$, Ju et al. showed that elevated NOX4 activity accelerates oxidation of NADH and supports increased glycolysis by generating $\mathrm{NAD}^{+}$, a substrate for GAPDH-mediated glycolytic reaction, promoting PDAC cell growth [18].

With more and more evidence showing that NOX4 mediates the metabolic reprogramming in different organs, the role of NOX4 in the regulation of PC cell metabolism and its mechanism deserve further exploration. Firstly, more in vivo experiments are needed to confirm that NOX4 could participate in the regulation of 
PC metabolic changes. Then, the specific mechanisms by which NOX4 regulates PC metabolism changes should be studied, such as whether they play roles in interfering with glycolysis-related proteins or activating certain downstream signaling pathways. Finding out the specific mechanisms how NOX4 regulates PC metabolic changes would help us make better strategies for PC treatment.

\section{NOX4 mediates angiogenesis in PC}

Angiogenesis is necessary for the invasive growth and metastasis of tumors and is an important target in the control of cancer progression [67]. Despite of conflicting views about the formation and recruitment of new blood vessels in human PDAC $[68,69]$, decades of studies demonstrate that PDAC, like other cancers, need new and destabilized blood vessels (tumor angiogenesis) as a prerequisite event for the growth and progression as well as dissemination of tumor cells for metastasis [70, 71].

Angiogenesis is a tightly regulated multistage process, including vessel sprouting, lumen formation and maturation [72]. Upon pro-angiogenic stimulation, endothelial cells (ECs) firstly sprout from the pre-existing vascellum after the degradation of ECM. Afterwards, these ECs undergo proliferation, migration and differentiation and recruit smooth muscle cells (SMCs) or pericytes to cover the newly-formed vessels to promote their maturation. The essential role of NOX4 in angiogenesis has been the subject of research for years. NOX4 is the major isoform of NADPH oxidases expressed in vascular cells and predominantly produce ROS, which play an important role in angiogenesis. In femoral artery ligation mice model, NOX4-/- mice exhibit attenuated angiogenesis, while endothelial-specific NOX4 transgenic mice exhibit enhanced angiogenesis and blood flow recovery under ischemia in an eNOS-dependent manner [73, 74]. Not only is involved in a variety of physiological processes, NOX4 also mediates angiogenesis in pathological conditions which can cause cancer.

Compelling evidence demonstrates that NOX4 and its generated ROS have a close relation to tumor angiogenesis in different cancers. In a carcinogen 3-methylcholanthrene (MCA)-induced fibrosarcoma mice model, NOX4 was proved to regulate the tumour-vessel density through stabilization of HIF- $1 \alpha$ and induction of VEGF expression, while a significant $38 \%$ reduction in tumour vascularization in fibrosarcomas of Nox4-/- mice [75]. In von Hippel Lindau (VHL)-deficient renal cell carcinoma, NOX4 also promotes renal tumorigenesis in a similar signal pathway via nuclear accumulation of HIF- $2 \alpha$ [76]. Li et al. showed that stable NOX4 knockdown reduced ROS production significantly and suppressed glioblastoma cells proliferation and invasion and tumor associated angiogenesis [77].
HIF-1 is a key transcription factor of angiogenesis in solid tumors including PC and NOX4 can regulate angiogenesis through HIF-1 in different cancers $[78,79]$. Thus, we assume that NOX4 may mediate angiogenesis in a similar way to promote the development of $\mathrm{PC}$ which need more studies to prove that.

\section{Perspective: Targeting NOX4 for the therapy of pancreatic cancer}

As NOX4 participates in the progress of PC via different ways, it has been emerging as a promising therapeutic target for PC treatment. We believe more studies are worth to do in some aspects. As discussed above, oncogenes mutation drives the development of PC. However, the carcinogenic mechanism of these mutant oncogenes remains exclusive. Recent studies showed that some oncogenes promote $\mathrm{PC}$ progress through interacting with NOX4. TP53 mutations could "switch" NOX4 from being protective and an indicator of good prognosis to deleterious by promoting programs favoring cancer progression including EMT, cell migration, cell adhesion, and angiogenesis [21]. Ju et al. found that NOX4 is the key point of interaction between $K R A S$ activation and P16 inactivation to promote the occurrence of pancreatic cancer [18]. According to the full exome group sequencing of $\mathrm{PC}$, KRAS, TP53, CDKN2A and SMAD4 are most common oncogenes. Therefore, more studies are needed to explore the relationship between NOX4 and other oncogenes, such as CDKN2A and SMAD4. If we could prove that a variety of genetic mutations play carcinogenic role in $\mathrm{PC}$ are associated with NOX4, then NOX4 would become the greatest target of $\mathrm{PC}$ as it could be applied to patients carrying different genetic mutations.

As presented in this review, NOX4 can participate in the development of PC via different mechanism, which prove that it could be a promising target for the PC treatment (Fig. 1). Although some studies have shown that pharmacological/genetic inhibition of NOX4 can inhibit tumor development at the cellular level or in animal models, the effectiveness in human still needs further clinic trial $[20,22]$. This is the second point we could explore.

Recent breakthroughs in cancer treatment consisting of new combinations of existing medications. Drug resistance is the main reason why chemotherapeutics cannot achieve the desired therapeutic effect. Interestingly, NOX4 may related to chemotherapy resistance $[80,81]$. Karthigayan et al. found NOX4 functions as a mitochondrial energetic sensor coupling cancer metabolic reprogramming to drug resistance [82]. In ovarian cancer cells, NOX4 knockdown increased sensitivity of targeted therapy and radiotherapy through decreased expression of HER3 and NF-kB p65 [12]. Ju et al. tested the impact of 


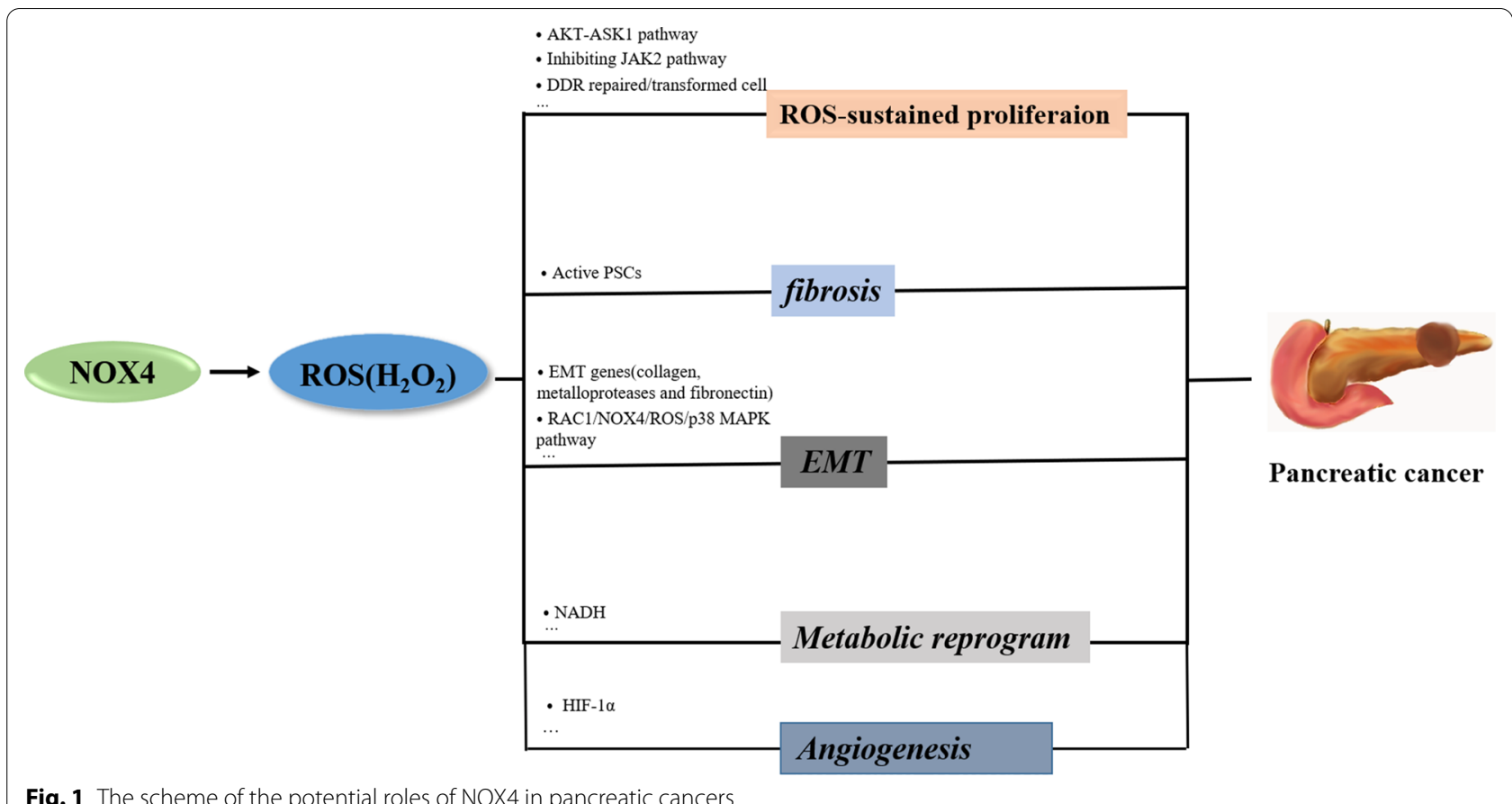

NOX4 inhibitors combined with gemcitabine on Panc1 cells-a human PDAC cell line carrying a mutant K-Ras allele.53, and observed that the combination therapy displayed a strong synergistic impact on reduced cell viability and enhanced apoptosis and it increased the half-maximal inhibitory concentration of gemcitabine by four- to sixfold [19]. These results indicated us that chemotherapy with NOX4 inhibitor may achieve better therapeutic effects in PC. This is the third and most important idea which we could test.

Therefore, research needs to further explore the role of NOX4 in PC progression and chemotherapy resistance, so that clinic can make individual treatment for PC patients to enhance drug efficacy, extending patient survival, and improve quality of life.

\section{Conclusion}

Despite rapid advances in modern medical technology and significant improvements in survival rates of many cancers, PC is still a highly lethal gastrointestinal cancer with a low 5-year survival rate and difficulty in early detection. Exploring the pathogenesis of PC and seeking its therapeutic targets has become an urgent issue.

NOX4 is one of the NOX family. Unlike most other subunits generating $\mathrm{O}_{2}^{-}$, NOX4 catalyzes the reduction of molecular oxygen to $\mathrm{H}_{2} \mathrm{O}_{2}$. This feature gives NOX4 some specific roles in different cellular functions, such as proliferation, differentiation, migration, apoptosis, senescence and matrix secretion [83-88]. NOX4 has been proven to participate in the development of PC by promoting cell proliferation, activation of PSCs, EMT progression, regulating cell metabolism changes and mediating angiogenesis. However, its specific mechanism of these effects is still exclusive and awaits further study. Since NOX4 is increased in PC and promotes PC development via variety ways, it may be a robust potential therapeutic target for PC. More researches also need focus on the therapeutic effect of NOX4 in PC.

Acknowledgements

Not applicable.

Authors' contributions

$Y B$ and $X L$ made the manuscript. CL and EL participated in the writing of paper and revision of manuscript. All authors read and approved the final manuscript.

\section{Funding}

This study was supported in part by the grants from New Technique Plan (No. XJS-202101), National Key R\&D Program of China (No. 2016YFC1303601) and National Natural Science Foundation of China (No. 82003387).

Availability of data and materials

The datasets are available under reasonable request.

\section{Declarations}

Ethics approval and consent to participate

Not applicable.

Consent for publication

Not applicable. 


\section{Competing interests}

The authors declare that they have no competing interests.

\section{Author details}

${ }^{1}$ Department of Gastroenterology and Hepatology, The First Medical Center of PLA General Hospital, Beijing 100853, China. ${ }^{2}$ Senior Department of Oncology, The Fifth Medical Center of PLA General Hospital, Beijing 100859, China.

\section{Received: 30 August 2021 Accepted: 3 December 2021}

Published online: 20 December 2021

\section{References}

1. Siegel RL, Miller KD, Jemal A. Cancer statistics. CA. 2020;70:7-30.

2. Rahib L, Smith BD, Aizenberg R, Rosenzweig AB, Fleshman JM, Matrisian LM. Projecting cancer incidence and deaths to 2030: the unexpected burden of thyroid, liver, and pancreas cancers in the United States. Can Res. 2014;74:2913-21.

3. Bailey P, Chang DK, Nones K, Johns AL, Patch AM, Gingras MC, Miller DK, Christ AN, Bruxner TJ, Quinn MC, Nourse C, Murtaugh LC, et al. Genomic analyses identify molecular subtypes of pancreatic cancer. Nature. 2016;531:47-52

4. Cortés-Ciriano I, Lee JJ, Xi R, Jain D, Jung YL, Yang L, Gordenin D, Klimczak LJ, Zhang CZ, Pellman DS, Park PJ. Comprehensive analysis of chromothripsis in 2,658 human cancers using whole-genome sequencing. Nat Genet. 2020;52:331-41.

5. Notta F, Chan-Seng-Yue M, Lemire M, Li Y, Wilson GW, Connor AA, Denroche RE, Liang SB, Brown AM, Kim JC, Wang T, Simpson JT, et al. A renewed model of pancreatic cancer evolution based on genomic rearrangement patterns. Nature. 2016:538:378-82.

6. Hayes JD, Dinkova-Kostova AT, Tew KD. Oxidative Stress in Cancer. Cancer Cell. 2020;38:167-97.

7. Moloney JN, Cotter TG. ROS signalling in the biology of cancer. Semin Cell Dev Biol. 2018;80:50-64.

8. Wu Y, Lu J, Antony S, Juhasz A, Liu H, Jiang G, Meitzler JL, Hollingshead M, Haines DC, Butcher D, Roy K, Doroshow JH. Activation of TLR4 is required for the synergistic induction of dual oxidase 2 and dual oxidase A2 by IFN- $\gamma$ and lipopolysaccharide in human pancreatic cancer cell lines. J Immunol. 2013;190:1859-72.

9. Meitzler JL, Antony S, Wu Y, Juhasz A, Liu H, Jiang G, Lu J, Roy K, Doroshow $\mathrm{JH}$. NADPH oxidases: a perspective on reactive oxygen species production in tumor biology. Antioxid Redox Signal. 2014;20:2873-89.

10. Panday A, Sahoo MK, Osorio D, Batra S. NADPH oxidases: an overview from structure to innate immunity-associated pathologies. Cell Mol Immunol. 2015;12:5-23.

11. Hiraga R, Kato M, Miyagawa S, Kamata T. Nox4-derived ROS signaling contributes to TGF- $\beta$-induced epithelial-mesenchymal transition in pancreatic cancer cells. Anticancer Res. 2013;33:4431-8.

12. Liu WJ, Huang YX, Wang W, Zhang Y, Liu BJ, Qiu JG, Jiang BH, Liu LZ. NOX4 signaling mediates cancer development and therapeutic resistance through HER3 in Ovarian Cancer Cells. Cells. 2021;10:9.

13. Carnesecchi S, Deffert C, Donati Y, Basset O, Hinz B, Preynat-Seauve O, Guichard C, Arbiser JL, Banfi B, Pache JC, Barazzone-Argiroffo C, Krause $\mathrm{KH}$. A key role for NOX4 in epithelial cell death during development of lung fibrosis. Antioxid Redox Signal. 2011;15:607-19.

14. Nisimoto Y, Diebold BA, Cosentino-Gomes D, Lambeth JD. Nox4: a hydrogen peroxide-generating oxygen sensor. Biochemistry. 2014;53:5111-20.

15. Vermot A, Petit-Härtlein I, Smith SME, Fieschi F. NADPH Oxidases (NOX): An Overview from Discovery, Molecular Mechanisms to Physiology and Pathology. Antioxidants (Basel, Switzerland) 2021;10.

16. Meitzler JL, Makhlouf HR, Antony S, Wu Y, Butcher D, Jiang G, Juhasz A, Lu J, Dahan I, Jansen-Dürr P, Pircher H, Shah AM, et al. Decoding NADPH oxidase 4 expression in human tumors. Redox Biol. 2017;13:182-95.

17. Lin XL, Yang L, Fu SW, Lin WF, Gao YJ, Chen HY, Ge ZZ. Overexpression of NOX4 predicts poor prognosis and promotes tumor progression in human colorectal cancer. Oncotarget. 2017:8:33586-600.

18. Ju HQ, Ying $H$, Tian T, Ling J, Fu J, Lu Y, Wu M, Yang L, Achreja A, Chen G, Zhuang Z, Wang H, et al. Mutant Kras- and p16-regulated NOX4 activation overcomes metabolic checkpoints in development of pancreatic ductal adenocarcinoma. Nat Commun. 2017;8:14437.
19. Ogrunc M, Di Micco R, Liontos M, Bombardelli L, Mione M, Fumagalli M, Gorgoulis VG, d'Adda di Fagagna F. Oncogene-induced reactive oxygen species fuel hyperproliferation and DNA damage response activation. Cell death and differentiation 2014;21:998-1012.

20. Jain P, Dvorkin-Gheva A, Mollen E, Malbeteau L, Xie M, Jessa F, Dhavarasa P, Chung S, Brown KR, Jang GH, Vora P, Notta F, et al. NOX4 links metabolic regulation in pancreatic cancer to endoplasmic reticulum redox vulnerability and dependence on PRDX4. Science advances 2021;7.

21. Ma WF, Boudreau HE, Leto TL. Pan-Cancer Analysis Shows TP53 Mutations Modulate the Association of NOX4 with Genetic Programs of Cancer Progression and Clinical Outcome. Antioxidants (Basel, Switzerland). 2021:10:834.

22. Hiraga R, Kato M, Miyagawa S, Kamata T. Nox4-derived ROS signaling contributes to TGF-beta-induced epithelial-mesenchymal transition in pancreatic cancer cells. Anticancer Res. 2013;33:4431-8.

23. Bedard K, Krause KH. The NOX family of ROS-generating NADPH oxidases: physiology and pathophysiology. Physiol Rev. 2007;87:245-313.

24. Ma M, Shi F, Zhai R, Wang H, Li K, Xu C, Yao W, Zhou F. TGF- $\beta$ promote epithelial-mesenchymal transition via NF-kB/NOX4/ROS signal pathway in lung cancer cells. Mol Biol Rep. 2021;48:2365-75.

25. Helfinger V, FreiherrvonGall F, Henke N, Kunze MM, Schmid T, Rezende F, Heidler J, Wittig I, Radeke HH, Marschall V, Anderson K, Shah AM, et al. Genetic deletion of Nox4 enhances cancerogen-induced formation of solid tumors. Proc Nat Acad Sci USA. 2021;118:56.

26. Tang P, Dang H, Huang J, Xu T, Yuan P, Hu J, Sheng JF. NADPH oxidase NOX4 is a glycolytic regulator through mROS-HIF1a axis in thyroid carcinomas. Sci Rep. 2018;8:15897.

27. Vaquero EC, Edderkaoui M, Pandol SJ, Gukovsky I, Gukovskaya AS. Reactive oxygen species produced by NAD(P)H oxidase inhibit apoptosis in pancreatic cancer cells. J Biol Chem. 2004;279:34643-54.

28. Lee JK, Edderkaoui M, Truong P, Ohno I, Jang KT, Berti A, Pandol SJ, Gukovskaya AS. NADPH oxidase promotes pancreatic cancer cell survival via inhibiting JAK2 dephosphorylation by tyrosine phosphatases. Gastroenterology. 2007;133:1637-48.

29. Mochizuki T, Furuta S, Mitsushita J, Shang WH, Ito M, Yokoo Y, Yamaura M, Ishizone S, Nakayama J, Konagai A, Hirose K, Kiyosawa K, et al. Inhibition of NADPH oxidase 4 activates apoptosis via the AKT/apoptosis signal-regulating kinase 1 pathway in pancreatic cancer PANC-1 cells. Oncogene. 2006;25:3699-707.

30. Calcinotto A, Kohli J, Zagato E, Pellegrini L, Demaria M, Alimonti A. Cellular Senescence: Aging, Cancer, and Injury. Physiol Rev. 2019;99:1047-78.

31. Cannon A, Thompson CM, Bhatia R, Armstrong KA, Solheim JC, Kumar S, Batra SK. Molecular mechanisms of pancreatic myofibroblast activation in chronic pancreatitis and pancreatic ductal adenocarcinoma. J Gastroenterol. 2021;56:689-703.

32. Zhao QD, Viswanadhapalli S, Williams P, Shi Q, Tan C, Yi X, Bhandari B, Abboud HE. NADPH oxidase 4 induces cardiac fibrosis and hypertrophy through activating Akt/mTOR and NFKB signaling pathways. Circulation. 2015;131:643-55

33. Hecker L, Logsdon NJ, Kurundkar D, Kurundkar A, Bernard K, HockT, Meldrum E, Sanders YY, Thannickal VJ. Reversal of persistent fibrosis in aging by targeting Nox4-Nrf2 redox imbalance. Sci Transl Med. 2014;6:23147.

34. Yang Q, Chen HY, Wang JN, Han HQ, Jiang L, Wu WF, Wei B, Gao L, Ma QY, Liu XQ, Chen Q, Wen JG, et al. Alcohol promotes renal fibrosis by activating Nox2/4-mediated DNA methylation of Smad7. Clin Sci. 2020;134:103-22.

35. Masamune A, Watanabe T, Kikuta K, Satoh K, Shimosegawa T. NADPH oxidase plays a crucial role in the activation of pancreatic stellate cells. Am J Physiol. 2008;294:108.

36. Hu R, Wang YL, Edderkaoui M, Lugea A, Apte MV, Pandol SJ. Ethanol augments PDGF-induced NADPH oxidase activity and proliferation in rat pancreatic stellate cells. Pancreatology. 2007;7:332-40.

37. Edderkaoui M, Hong P, Vaquero EC, Lee JK, Fischer L, Friess H, Buchler MW, Lerch MM, Pandol SJ, Gukovskaya AS. Extracellular matrix stimulates reactive oxygen species production and increases pancreatic cancer cell survival through 5-lipoxygenase and NADPH oxidase. Am J Physiol. 2005;289:G1137-47.

38. Bachem MG, Zhou Z, Zhou S, Siech M. Role of stellate cells in pancreatic fibrogenesis associated with acute and chronic pancreatitis. J Gastroenterol Hepatol. 2006;21(Suppl 3):S92-6. 
39. Zhang DY, Goossens N, Guo J, Tsai MC, Chou HI, Altunkaynak C, Sangiovanni A, lavarone M, Colombo M, Kobayashi M, Kumada H, Villanueva A, et al. A hepatic stellate cell gene expression signature associated with outcomes in hepatitis C cirrhosis and hepatocellular carcinoma after curative resection. Gut. 2016;65:1754-64.

40. Jin G, Hong W, Guo Y, Bai Y, Chen B. Molecular mechanism of pancreatic stellate cells activation in chronic pancreatitis and pancreatic cancer. J Cancer. 2020;11:1505-15.

41. Affo $S$, Yu LX, Schwabe RF. The role of cancer-associated fibroblasts and fibrosis in liver cancer. Annu Rev Pathol. 2017;12:153-86.

42. Huang C, Gan D, Luo F, Wan S, Chen J, Wang A, Li B, Zhu X. Interaction Mechanisms Between the NOX4/ROS and RhoA/ROCK1 Signaling Pathways as New Anti- fibrosis Targets of Ursolic Acid in Hepatic Stellate Cells. Front Pharmacol. 2019;10:431.

43. Huang Y, Li Y, Lou A, Wang GZ, Hu Y, Zhang Y, Huang W, Wang J, Li Y, Zhu X, Chen T, Lin J, et al. Alamandine attenuates hepatic fibrosis by regulating autophagy induced by NOX4-dependent ROS. Clin Sci. 2020;134:853-69.

44. Chen L, Zhou T, White T, O'Brien A, Chakraborty S, Liangpunsakul S, Yang Z, Kennedy L, Saxena R, Wu C, Meng F, Huang Q, et al. The Apelin-Apelin Receptor Axis Triggers Cholangiocyte Proliferation and Liver Fibrosis During Mouse Models of Cholestasis. Hepatology. 2021;73:2411-28.

45. Chen Y, Zhao C, Liu X, Wu G, Zhong J, Zhao T, Li J, Lin Y, Zhou Y, Wei Y. Plumbagin ameliorates liver fibrosis via a ROS-mediated NF-кB signaling pathway in vitro and in vivo. Biomed Pharmacother. 2019;116:108923.

46. Cheng Q, Li C, Yang CF, Zhong YJ, Wu D, Shi L, Chen L, Li YW, Li L. Methyl ferulic acid attenuates liver fibrosis and hepatic stellate cell activation through the TGF- $\beta 1 /$ Smad and NOX4/ROS pathways. Chem Biol Interact. 2019;299:131-9.

47. Jiang JX, Chen X, Serizawa N, Szyndralewiez C, Page P, Schröder K, Brandes RP, Devaraj S, Török NJ. Liver fibrosis and hepatocyte apoptosis are attenuated by GKT137831, a novel NOX4/NOX1 inhibitor in vivo. Free Radical Biol Med. 2012;53:289-96.

48. Sancho P, Mainez J, Crosas-Molist E, Roncero C, Fernández-Rodriguez CM, Pinedo F, Huber H, Eferl R, Mikulits W, Fabregat I. NADPH oxidase NOX4 mediates stellate cell activation and hepatocyte cell death during liver fibrosis development. PLOS ONE. 2012;7:e45285.

49. Shibue T, Weinberg RA. EMT, CSCS, and drug resistance: the mechanistic link and clinical implications. Nat Rev Clin Oncol. 2017;14:611-29.

50. Rodriguez-Aznar E, Wiesmüller L, Sainz B Jr, Hermann PC. EMT and stemness-key players in pancreatic cancer stem cells. Cancers. 2019;11:89.

51. Arumugam T, Ramachandran V, Fournier KF, Wang H, Marquis L, Abbruzzese JL, Gallick GE, Logsdon CD, McConkey DJ, Choi W. Epithelial to mesenchymal transition contributes to drug resistance in pancreatic cancer. Can Res. 2009;69:5820-8.

52. Rhim AD, Mirek ET, Aiello NM, Maitra A, Bailey JM, McAllister F, Reichert M, Beatty GL, Rustgi AK, Vonderheide RH, Leach SD, Stanger BZ. EMT and dissemination precede pancreatic tumor formation. Cell. 2012;148:349-61.

53. Alvarez MA, Freitas JP, Mazher Hussain S, Glazer ES. TGF- $\beta$ inhibitors in metastatic pancreatic ductal adenocarcinoma. J Gastrointest Cancer. 2019;50:207-13.

54. Radisky DC, Levy DD, Littlepage LE, Liu H, Nelson CM, Fata JE, Leake D, Godden EL, Albertson DG, Nieto MA, Werb Z, Bissell MJ. Rac1b and reactive oxygen species mediate MMP-3-induced EMT and genomic instability. Nature. 2005;436:123-7.

55. Micalizzi DS, Farabaugh SM, Ford HL. Epithelial-mesenchymal transition in cancer: parallels between normal development and tumor progression. J Mammary Gland Biol Neoplasia. 2010;15:117-34.

56. Lee SJ, Kim SJ, Jo DH, Park KS, Kim JH. Blockade of mTORC1-NOX signaling pathway inhibits TGF- $\beta 1$-mediated senescence-like structural alterations of the retinal pigment epithelium. FASEB J. 2021;35:e21403.

57. Crosas-Molist E, Bertran E, Rodriguez-Hernandez I, Herraiz C, Cantelli G, Fabra À, Sanz-Moreno V, Fabregat I. The NADPH oxidase NOX4 represses epithelial to amoeboid transition and efficient tumour dissemination. Oncogene. 2017;36:3002-14.

58. Boudreau HE, Casterline BW, Rada B, Korzeniowska A, Leto TL. Nox4 involvement in TGF-beta and SMAD3-driven induction of the epithelialto-mesenchymal transition and migration of breast epithelial cells. Free Radical Biol Med. 2012;53:1489-99.

59. Kim YM, Muthuramalingam K, Cho M. Redox Regulation of NOX Isoforms on FAK((Y397))/SRC((Y416)) Phosphorylation Driven
Epithelial-to-Mesenchymal Transition in Malignant Cervical Epithelial Cells. Cells. 2020;9:12.

60. Witte D, Bartscht T, Kaufmann R, Pries R, Settmacher U, Lehnert H, Ungefroren $\mathrm{H}$. TGF- $\beta 1$-induced cell migration in pancreatic carcinoma cells is RAC1 and NOX4-dependent and requires RAC1 and NOX4-dependent activation of p38 MAPK. Oncol Rep. 2017;38:3693-701.

61. Li H, Peng C, Zhu C, Nie S, Qian X, Shi Z, Shi M, Liang Y, Ding X, Zhang S, Zhang B, Li X, et al. Hypoxia promotes the metastasis of pancreatic cancer through regulating NOX4/KDM5A-mediated histone methylation modification changes in a HIF1A-independent manner. Clin Epigenetics. 2021:13:18.

62. Pavlova NN, Thompson CB. The Emerging Hallmarks of Cancer Metabolism. Cell Metab. 2016;23:27-47.

63. Galluzzi L, Kepp O, Vander Heiden MG, Kroemer G. Metabolic targets for cancer therapy. Nat Rev Drug Discovery. 2013;12:829-46.

64. Yu T, Li L, Liu W, Ya B, Cheng H, Xin Q. Silencing of NADPH Oxidase 4 Attenuates Hypoxia Resistance in Neuroblastoma Cells SH-SY5Y by Inhibiting PI3K/Akt-Dependent Glycolysis. Oncol Res. 2019;27:525-32.

65. Zeng C, Wu Q, Wang J, Yao B, Ma L, Yang Z, Li J, Liu B. NOX4 supports glycolysis and promotes glutamine metabolism in non-small cell lung cancer cells. Free Radical Biol Med. 2016;101:236-48.

66. Wu D, Huang RT, Hamanaka RB, Krause M, Oh MJ, Kuo CH, Nigdelioglu R, Meliton AY, Witt L, Dai G, Civelek M, Prabhakar NR, et al. HIF-1a is required for disturbed flow-induced metabolic reprogramming in human and porcine vascular endothelium. Elife. 2017;6:230.

67. Folkman J. Role of angiogenesis in tumor growth and metastasis. Semin Oncol. 2002;29:15-8.

68. van der Zee JA, van Eijck CH, Hop WC, van Dekken H, Dicheva BM, Seynhaeve AL, Koning GA, Eggermont AM, ten Hagen TL. Angiogenesis: a prognostic determinant in pancreatic cancer? European journal of cancer (Oxford. England. 1990;2011(47):2576-84.

69. Ellis LM, Takahashi Y, Fenoglio CJ, Cleary KR, Bucana CD, Evans DB. Vessel counts and vascular endothelial growth factor expression in pancreatic adenocarcinoma. Eur J Cancer. 1998;34:337-40.

70. Vermeulen PB, Gasparini G, Fox SB, Colpaert C, Marson LP, Gion M, Beliën JA, de Waal RM, Van Marck E, Magnani E, Weidner N, Harris AL, et al. Second international consensus on the methodology and criteria of evaluation of angiogenesis quantification in solid human tumours. Eur J Cancer. 2002;38:1564-79.

71. Whipple C, Korc M. Targeting angiogenesis in pancreatic cancer: rationale and pitfalls. Langenbecks Arch Surg. 2008;393:901-10.

72. Cai WX, Liang L, Wang L, Han JT, Zhu XX, Han H, Hu DH, Zhang P. Inhibition of Notch signaling leads to increased intracellular ROS by up-regulating Nox4 expression in primary HUVECs. Cell Immunol. 2014;287:129-35.

73. Schröder K, Zhang M, Benkhoff S, Mieth A, Pliquett R, Kosowski J, Kruse C, Luedike P, Michaelis UR, Weissmann N, Dimmeler S, Shah AM, et al. Nox4 is a protective reactive oxygen species generating vascular NADPH oxidase. Circ Res. 2012;110:1217-25.

74. Craige SM, Chen K, Pei Y, Li C, Huang X, Chen C, Shibata R, Sato K, Walsh $K$, Keaney JF Jr. NADPH oxidase 4 promotes endothelial angiogenesis through endothelial nitric oxide synthase activation. Circulation. 2011;124:731-40.

75. Helfinger V, Henke N, Harenkamp S, Walter M, Epah J, Penski C, Mittelbronn M, Schröder K. The NADPH Oxidase Nox4 mediates tumour angiogenesis. Acta Physiol (Oxf). 2016;216:435-46.

76. Gregg JL, Turner RM 2nd, Chang G, Joshi D, Zhan Y, Chen L, Maranchie JK. NADPH oxidase NOX4 supports renal tumorigenesis by promoting the expression and nuclear accumulation of HIF2a. Can Res. 2014;74:3501-11.

77. Li Y, Han N, Yin T, Huang L, Liu S, Liu D, Xie C, Zhang M. Lentivirus-mediated Nox4 shRNA invasion and angiogenesis and enhances radiosensitivity in human glioblastoma. Oxid Med Cell Longevity. 2014;2014:581732.

78. Leo C, Giaccia AJ, Denko NC. The hypoxic tumor microenvironment and gene expression. Semin Radiat Oncol. 2004;14:207-14.

79. Kung AL, Wang S, Klco JM, Kaelin WG, Livingston DM. Suppression of tumor growth through disruption of hypoxia-inducible transcription. Nat Med. 2000;6:1335-40

80. Chang G, Chen L, Lin HM, Lin Y, Maranchie JK. Nox4 inhibition enhances the cytotoxicity of cisplatin in human renal cancer cells. J Exp Ther Oncol. 2012;10:9-18. 
81. Kaushik D, Ashcraft KA, Wang H, Shanmugasundaram K, Shah PK, Gonzalez G, Nazarullah A, Tye CB, Liss MA, Pruthi DK, Mansour AM, Chowdhury W, et al. Nuclear NADPH oxidase-4 associated with disease progression in renal cell carcinoma. Transl Res. 2020;223:1-14.

82. Shanmugasundaram K, Nayak BK, Friedrichs WE, Kaushik D, Rodriguez R, Block K. NOX4 functions as a mitochondrial energetic sensor coupling cancer metabolic reprogramming to drug resistance. Nat Commun. 2017;8:997.

83. Hecker L, Vittal R, Jones T, Jagirdar R, Luckhardt TR, Horowitz JC, Pennathur S, Martinez FJ, Thannickal VJ. NADPH oxidase-4 mediates myofibroblast activation and fibrogenic responses to lung injury. Nat Med. 2009;15:1077-81.

84. Petry A, Djordjevic T, Weitnauer M, Kietzmann T, Hess J, Görlach A. NOX2 and NOX4 mediate proliferative response in endothelial cells. Antioxid Redox Signal. 2006;8:1473-84.

85. Clempus RE, Sorescu D, Dikalova AE, Pounkova L, Jo P, Sorescu GP, Schmidt HH, Lassègue B, Griendling KK. Nox4 is required for maintenance of the differentiated vascular smooth muscle cell phenotype. Arterioscler Thromb Vasc Biol. 2007;27:42-8.

86. Kim J, Yoo JY, Suh JM, Park S, Kang D, Jo H, Bae YS. The flagellin-TLR5-Nox4 axis promotes the migration of smooth muscle cells in atherosclerosis. Exp Mol Med. 2019:51:1-13.

87. Pedruzzi E, Guichard C, Ollivier V, Driss F, Fay M, Prunet C, Marie JC, Pouzet C, Samadi M, Elbim C, O'Dowd Y, Bens M, et al. NAD(P)H oxidase Nox-4 mediates 7-ketocholesterol-induced endoplasmic reticulum stress and apoptosis in human aortic smooth muscle cells. Mol Cell Biol. 2004;24:10703-17.

88. Canugovi C, Stevenson MD, Vendrov AE, Hayami T, Robidoux J, Xiao H, Zhang YY, Eitzman DT, Runge MS, Madamanchi NR. Increased mitochondrial NADPH oxidase 4 (NOX4) expression in aging is a causative factor in aortic stiffening. Redox Biol. 2019;26:101288.

\section{Publisher's Note}

Springer Nature remains neutral with regard to jurisdictional claims in published maps and institutional affiliations.

- fast, convenient online submission

- thorough peer review by experienced researchers in your field

- rapid publication on acceptance

- support for research data, including large and complex data types

- gold Open Access which fosters wider collaboration and increased citations

- maximum visibility for your research: over $100 \mathrm{M}$ website views per year

At BMC, research is always in progress.

Learn more biomedcentral.com/submissions 